\title{
HOW I GROW: Months Eleven and Twelve ${ }^{1}$
}

Millie Ferrer and Anne M. Fugate ${ }^{2}$

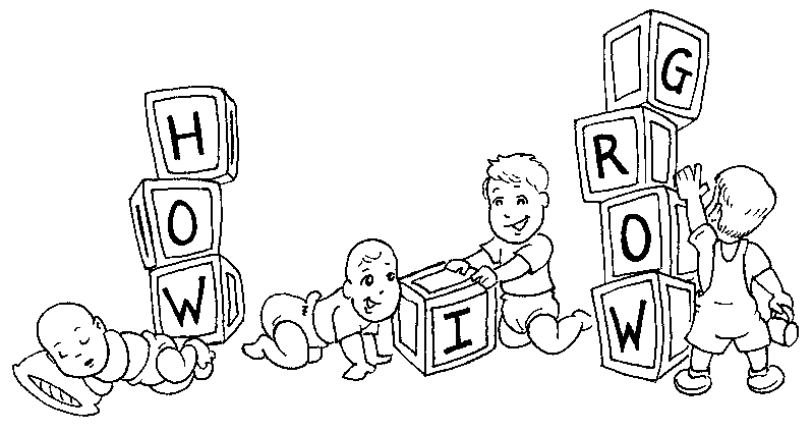

Can you believe your baby is nearing a year old? Your baby has changed so much! He has grown from a helpless newborn not able to do much, into an active 11-month-old who can do a great deal. Now he can move around and explore on his own. He is very curious and is doing and learning more all the time. He has developed a personality all his own, showing a range of emotions, a sense of humor, and likes and dislikes. He has become a unique member of your family.

As much as your baby has grown in the past months, so have you grown as a parent. You have learned about your baby as a unique individual and how to care for and nurture him during these months of his development. You play such an important role in your baby's life. Continue to learn as much as possible about the different milestones of development and your baby's unique temperament. Your baby benefits tremendously as you keep growing and learning as a parent.
During these months, your adventurous baby needs you to provide a safe place to explore. Having the freedom to explore, plus your encouragement, will help your baby learn. Your baby also needs reasonable limits. Reasonable limits keep your baby safe and begin to teach him necessary boundaries. In addition to keeping him safe, boundaries also help him learn how to interact with others. By providing both the freedom to explore and safe, reasonable limits, you will help your baby develop physically, socially, emotionally, and intellectually.

\section{Physical Development}

Your baby has become very active and mobile. She can crawl quickly. She can stand on her own holding onto furniture and move all around a room. She can bend down or squat to get a toy and get back up. She is so pleased with her physical abilities that she stays in motion most of the day. She wants to practice and to learn how to do even more.

Your baby may have recently started climbing low heights, such as a stair. If not, she will soon. Once she masters a low height, she will try to go even higher, onto a chair or sofa. Climbing is fun and exciting for your baby. Now she can see more than just standing on the floor. Teach her how to get down safely, feet first, and let her climb up the

1. This document is FCS2222, one of a series of the Department of Family, Youth and Community Sciences, Florida Cooperative Extension Service, University of Florida, IFAS, Gainesville FL 32611. First published: August 2003. Reviewed by Keith Gouin, coordinator educational/training programs; Meredith Taylor, county extension director and extension agent IV; Live Oak; and Gayle Whitworth, extension agent I, Cocoa, FL. Thanks to Jason Greene for creating the artwork in this fact sheet. Please visit the EDIS Web site at http://edis.ifas.ufl.edu

2. Millie Ferrer, Ph.D., professor; and Anne M. Fugate, former coordinator educational/training program Department of Family, Youth and Community Sciences, University of Florida, IFAS, Gainesville, FL 32611. 
the stairs or onto furniture as you watch. Continue to keep stairs off limits unless you can watch your baby.

For a while, your baby has been able to stand while holding onto your hands. Now she may have started to walk a few steps without holding on. If not, she will start soon. Help your baby practice walking and

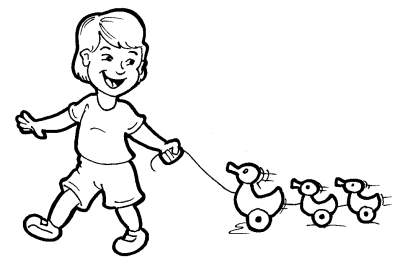
encourage her efforts. Soon, around her first birthday or shortly after, she will start walking on her own. In her enthusiasm for learning how to walk, she will probably resist eating and taking naps. This phase will soon pass.

During these months, your baby's control of her small muscles is steadily improving. You can see the improvement especially in her greater control of her hands. Her thumb and forefinger grasp has become very good. She can pick up things as small as a cracker crumb. By the end of these months, your baby will be able to point with her index finger. She will be able to hold a thick pencil or crayon and make marks on paper. She will be able to open packages, squeeze tubes, and remove lids (though probably not screw tops yet).

Your baby will continue to enjoy many of the games that helped her practice small muscle movements for the last month or so. For example, she will still enjoy playing with pop-up toys, emptying and refilling containers, and stacking blocks or plastic bowls. Continue to play these games with her, and try adding extra challenges. Give your baby pegboards or puzzles with large pieces. These games require her to fit shapes together fairly precisely.

By now, your baby probably insists on feeding herself. It makes mealtimes longer and messier, but it is also great practice in using her hands. Be patient and praise your baby as she uses her spoon and cup. Very likely your baby also wants to help dress and undress herself. She probably moves her arms and legs to help you.

Now that your baby is able to move around so well and get into everything more easily, you have to be more alert for safety hazards. For example, remove crib bumpers, so that your baby cannot use them to climb out of her crib. Make sure she cannot reach a window from her crib. In the kitchen, make sure to turn pot handles inward on the stove, so that your baby does not grab one. Watch that she does not try to climb onto a kitchen counter from a chair. Watch that she does not pick up small, unsafe objects, such as pins or aspirin, that might have fallen on the floor unnoticed. If there is any chance your baby can undo safety latches on cabinets, move dangerous substances high out of reach. Your baby loves to explore and practice her physical skills, so make sure she can do so safely.

\section{Social Development}

During these months, your baby enjoys interacting with you as much as ever. He still likes to play imitation games, copying your sounds and movements. He likes to do things you ask of him, such as "blow me a kiss" or "wave bye-bye". He also likes to play mirror games. Set him in front of a mirror and ask, "Where's Jaimie?" Encourage him to point to himself in the mirror. Then put your face next to his and ask, "Where's Mommy?" or "Where's Daddy"?

At 11 or 12 months, your baby can also play alone for fifteen or twenty minutes at a time. It is healthy for your baby to spend time playing alone, because he learns how to entertain himself. At this age, he may watch or play alongside other

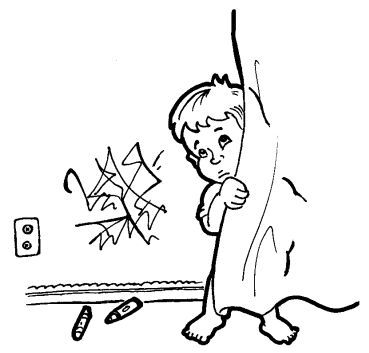
children, but he will not really play with them. 
Though your baby can play by himself now, he still needs and wants your attention. Often he wants to show you what he has discovered or what he can do. Talk to him about what he shows you. Smile, clap, and praise him when he demonstrates what he can do. When you show interest in his activities, you nurture his curiosity and encourage him to learn.

Sometimes your baby will want your assistance or attention at a moment when your hands are full. It is okay to occasionally tell your baby that he will have to wait a minute. It helps him to learn that others' needs are important, too.

Your baby is learning about how his world works and is developing a sense of independence. During this time, he will probably test you to see what he can get away with. Even when you tell him not to do something, he may do it anyway. It is important to set and enforce limits with your baby. Limits help keep him safe and prevent him from being spoiled. Below are some guidelines for disciplining your baby.

- Try to prevent problems. Remember, your baby is an active, curious 11- or 12-monthold who wants to explore everything. Try to avoid situations in which you have to say "no" or "don't touch" all the time. In your own home, you can move breakable or unsafe objects out of reach. In public, be prepared to walk around with your baby or distract him with a toy.

- Make your expectations clear. When your baby is behaving inappropriately, redirect his attention. In short, simple phrases, tell him what he can do. Since he loves to imitate you, show him how to behave. For example, show him "the nice way to pet the kitty."

- Be consistent and follow through on what you say. Even when your baby becomes angry or cries, stick with your limits.

- Be kind, gentle, and patient. Remember, your baby wants your attention and approval. Keep showing him what you want him to do, and encourage him with smiles, hugs, and praise.
Your baby can tell when you are displeased with his behavior. He may cry or try to hide. It is okay to show your displeasure. Just make sure you do not make him feel that he is a bad person. Simply say in a firm, calm voice, "I am angry that you did that". By doing so, you set a good example for how to express anger without yelling, name-calling, or hitting.

\section{Emotional Development}

Your 11- or 12-month old can be a joy to be around. She has a sense of humor and laughs when she thinks something is funny. She shows affection to you and other people she loves. She shows excitement and pride when she discovers or accomplishes something.

Your baby also has more moments that are difficult. She is very definite about her likes and dislikes and she is also developing a sense of independence. This is part of your baby's healthy development. However, if something does not go her way, she

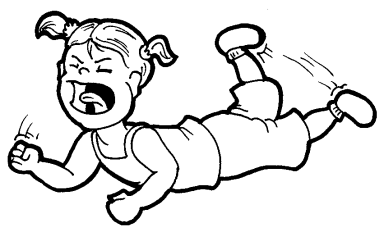
may pout or declare "no" very loudly. She may even have a temper tantrum. If your baby has a temper tantrum because she is unable to do something, teach her how to do it. If she has a tantrum because she is forbidden to do something, try to distract her with another activity. If distracting her does not work, make sure she is safe and ignore her. Stay nearby, but do not pay attention to her until she calms down. When she does, give her a hug and talk about her feelings.

Your baby is excited by and proud of what she is learning to do, but the move towards independence can also be a little scary or confusing for her. She might say "no," even when she means "yes". She will probably still cling to you around new people or in new situations. When she starts to learn to walk, she may come to you often for reassurance. Be patient and encouraging with your baby. Tell her how much you love her and how important she is to you. Give her hugs and kisses and some undivided attention every day. 


\section{Intellectual Development}

During these months, it may almost seem like you are living with a little scientist. Your baby is very curious and will spend a lot of time investigating things. He will stare at an object, feel it, mouth it, move it, and stare at it some more. He will repeatedly open and close things such as cabinets, books, plastic bowls with lids, and popup toys. He will repeatedly empty and refill drawers, boxes, laundry baskets, and other containers. He will stack things on top of each other and fit them inside of each other. If he tries to do something one way, but that way does not work, he will try another.

Even though your baby explores on his own now, interaction with you is still an important part of his learning process. You help him sort out everything he is learning. Talk to your baby about the things he is investigating. Show him how an object compares to other objects in size, shape, feel, and sound. Occasionally show him a new way to play with an object.

Your baby enjoys playing games that let him practice his skills. For example, put an object in a

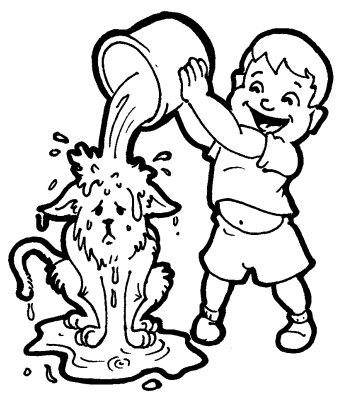
paper bag and ask your baby, "What's in the bag"? He will have fun opening the bag and investigating the new object. He will also have fun dropping objects into different containers or discovering which cup a toy is under.

At 11 months, your baby probably understands several words, such as his name, "bottle," "no," or "ball," and he will probably learn a couple more by his first birthday. By 12 months, babies usually understand five to ten words. Your baby probably also follows simple directions, such as "sit down" or "get your ball". To help your baby learn language, continue to talk with him as you have been. That is, talk to him about what you both are doing. Point to objects and name them. Read books to him, preferably books with big pictures of familiar objects.
You can also help your baby learn language by playing games in which you ask him to do something. For example, teach your baby the parts of the body by playing "Where is your...?" Point to your nose and say, "This is mommy's/daddy's nose. Where is your nose?" For another game, line up two or three different toys, such as a ball, a block, and a car, and ask your baby to bring one of them to you. You can also let your baby "help" you around the house by leaving out an item, such as a dishtowel, and asking him to bring it to you. When you first play a game with your baby, he might not understand your words. Show him what to do as you repeat them. Give your baby plenty of encouragement and eventually he will copy you. When he does what you ask, smile, clap, and praise him.

Your baby still babbles a lot, both when he is with you and when he is alone. His babbling is probably beginning to sound like phrases and sentences. He may also say a few words, such as "mama," "dada," or "ball," which he will say over and over. Keep playing dialogue games with him. Make a noise or say a word and encourage him to respond. Your baby loves your attention. The more you encourage him, the more he will make noise and try to talk.

If your baby does not say any words yet, do not worry. Babies usually say their first words between eight and fifteen months. What is important at this point is the amount of babbling and noisemaking he does and whether he shows that he understands some words. Also do not worry if your baby does not babble or talk as much when he begins to learn to walk. When babies start to learn to walk, they tend to put all of their effort into it and slow down on learning to talk.

If your baby does say a few words, he will probably try to use them to communicate with you. It is often hard to understand what he means, though, because he uses one word to express a whole thought. For example, when he says, 
"Dada," does he mean "I want to go with Dada?" or "Where is Dada"? Even if you do not know exactly what your baby means, respond when he tries to talk to you. For example, if he says "ball," say to him, "Yes, that is your red ball. Do you want to throw it?" By showing interest when your baby talks, you encourage him to talk more.

\section{Parent Time}

Congratulations! You are about to complete your first year of parenting. How both of you have grown together! This year has brought extraordinary joys, but also challenges. Seeing your baby master the developmental milestones of rolling over, sitting,

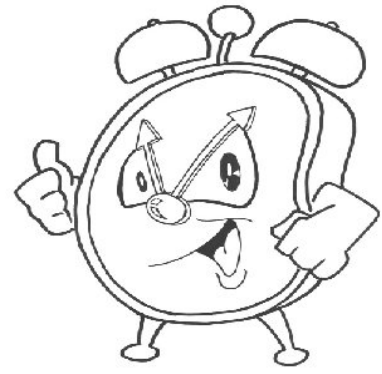
standing, and - possibly — walking, is joyous. Hearing your baby cry and not knowing why and not being able to console her can be painful.

As your infant reaches toddlerhood, you will need to continue using some important parenting tools. These include infinite patience, empathy and understanding, knowledge about ageappropriate expectations, and effective discipline techniques. These tools will assist you in raising a healthy child who is confident, nurturing, and selfdisciplined.

Remember to enlist the support of family and friends, as well as spiritual resources. Their support can help you raise a more secure and socially competent child. All children need a caring network of family and friends where they can feel safe and confident.

Last, but not least, remember to take care of yourself. Everyone needs time to himself or herself. The time you take to pamper yourself will make a difference in your stress level. Meditate, sit and enjoy your favorite music or go for an outing by yourself. In other words, take time to do the things you enjoy most. All of us need tender loving care!

\section{References}

Berk, Laura, E. 2002. Infants and Children: Prenatal Through Middle Childhood $4^{\text {th }}$ Ed. Boston: Allyn \& Bacon.

Nelson, Patricia. 1995.Great Beginnings: A Series for Parents of Infants and Young Children. Retrieved March 26, 2002, from the University of Delaware, National Cooperative Extension Web site: http://ag.udel.edu/extension/fam/gb/gb-list.htm

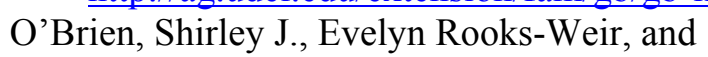
Suzanna Smith. 1996 Your Baby's First Year: Development During Month Eleven. University of Florida/IFAS Fact Sheet HE2042.

O'Brien, Shirley J., Evelyn Rooks-Weir and Suzanna Smith. 1996 Your Baby's First Year: Development During Month Twelve. University of Florida/IFAS Fact Sheet HE2043.

University of Maine Cooperative Extension. 2002 The Growing Years. Retrieved April 13, 2003, from the University of Maine Cooperative Extension_Web_site: http://www.umext.maine.edu/onlinepubs/htmpui bs/4226.htm

White, Burton, L. 1995. The New First Three Years of Life. New York: Simon \& Schuster.

White, Burton, L. 1994. Raising a Happy Unspoiled Child. New York: Simon \& Schuster. 